\title{
FROM RECEPTION TO HOSPITALITY: CULTURAL, METHODOLOGICAL AND ECONOMIC ASPECTS OF THE LABORATORY CIRCO IN ROME
}

DOI: 10.18485/arh_pt.2020.7.ch48

\section{_ Francesco Careri}

Department of Architecture, University of RomaTre, francesco.careri@uniroma3.it

\section{- Fabrizio Finucci}

Department of Architecture, University of Roma Tre, fabrizio.finucci@uniroma3.it

\section{_ Chiara Luchetti}

Department of Architecture, University of Roma Tre, chi.luchetti@gmail.com

\section{_ Alberto Marzo \\ Dep. of Civil, Constructional and Environmental Engineering, Sapienza, al.marzo89@gmail.com}

\section{_ Sara Monaco}

Department of Architecture, University of

RomaTre, sara.monaco25@gmail.com

\section{_ Serena Olcuire}

Dep. of Civil, Constructional and Environmental

Engineering, Sapienza, serena.olcuire@uniroma1.it

\section{_ Enrico Perini \\ Department of Architecture, University of Roma Tre, enrico.perini@gmail.com \\ _ Maria Rocco \\ Department of Architecture, University of RomaTre, marimaria.rocco@gmail.com}

\section{ABSTRACT}

The so-called 'refugee crisis' has spread a sense of emergency in the management of migrants' arrivals in Europe making extraordinary reception facilities a structural feature of the Italian system and fostering interventions by non-governmental organizations to support vulnerable people. At the local level, the emergency generates urban policies that blend security and decorum, depicting minorities and urban poor as undesirable subjects to be pushed at the margins of the socio-spatial order. The welfare shrinkage, born out of austerity policies, pushed local authorities to curb migrants' access to territorial rights such as social services. This lack of formal welfare leads migrants to rely on informal social networks, showing their capacity to construct their own paths of socio-spatial insertion in a new environment. The diversity of urban solidarity experiences - local associations, urban movements and individual citizens - creates an autonomous infrastructure of resistance to security policies and put in question the dominant nationalism. Drawing on these experiences in Rome, CIRCO proposes to rethink migrants' reception through the mutual concept of hospitality, 
with the aim of generating new forms of reciprocity and cohabitation. CIRCO (acronym for house indispensable for civic recreation and hospitality) is active in the Architectural and Urban Design Laboratory of the master's degree program in Urban Design of the Roma Tre University. Starting from the reuse of abandoned buildings and opening them to mobile populations and all the urban inhabitants, CIRCO reinterprets the temporariness and coexistence of diversity to trigger a process of collaborative construction of spaces for democracy, exchange, work and sociability, able to produce fractures in the territory of urban speculation, and build emancipatory paths to the right to dwelling. The paper presents a summary of the three years of activity of CIRCO: from the methodological and cultural system, to the production of urban "waste" maps, up to the synthetic proposal of some design scenarios.

KEYWORDS _ migrants, hospitality, building reuse, collaborative constructions

\section{INTRODUCTION}

The theme of migratory flows is showing a heavy inadequacy of the various political bodies, trapped among decision-makers in the continuous search for consensus and at the mercy of the altered perceptions spread in the population towards the phenomenon. For example, the worldwide sensation that migratory flows will lead to the total turnover of the population is cited, while the number of people living in a country different than the native one is around 245 million, just over $3 \%$ of the world population [IOM , 2018]. In 30 years the percentage has grown by a few decimal places (it was $2.9 \%$ in 1990). In Italy, $73 \%$ of people perceive the presence of immigrants to $25 \%$ of the population, when the real figure oscillates between 7 and $8 \%$. The increase in crime related to the increase in migrants is a further distortion, since, from 2011 to today, the number of foreign residents has risen by $16 \%$ and the reported crimes have decreased by $10 \%$ [Eurostat 2019]. The crises related to migratory flows highlight the inability of the European system (and national systems) to provide answers to a phenomenon that is no longer as emergency as structural. In particular, innovative or experimental approaches that attempt to tackle the problem in alternative ways are in short supply. The only practice of distinguishing between regular and irregular migrants becomes the source of a harmful hierarchy between those who have access to rights and the territory and those who see these rights denied through standardized criteria of victimization and vulnerability, that form a real humanitarian frontier [Walters, 2009]. The emergency approach has made the extraordinary reception structures the main feature of the Italian system [Campesi, 2018], stimulating the emergence of distinct segments: asylum seekers are forced to enter clandestinely and face the regularization process but are still included in the formal circuit, while, those who are not recognized as worthy of protection are forced to remain in a state of invisibility and blackmail. This condition influences the recognition of fundamental rights such as work, home, health, education and all other rights related to the presence in a territory. In Italy, many people move away from institutional assistance paths both because of the need to freely choose where to apply for asylum (and where to go to live), and because the housing conditions offered by the reception system force strict rules, such as timetables (wake up call, return, forced exit, meal delivery) without the possibility of choosing or preparing your own food, and without the possibility of being able to share it with other people who are not guests of the center. These restrictions, motivated by the management needs of hygiene and safety, end up harming privacy and infantilizing adult people in their daily lives, effectively preventing the construction of any sense of home, limiting themselves to providing accommodation for the satisfaction of primary needs. The CIRCO Lab, active in the Architectural and Urban Design Laboratory of the master's degree program in Urban Design of the Roma Tre University, proposes a rethinking of the reception spaces by starting from the abandoned empty spaces of the city by re-inserting them into an innovative process of reuse and management. 


\section{FUNDAMENTALS AND METHODOLOGY OF THE CIRCO PROJECT}

CIRCO arises from the observation of the limits of current reception policies, from the recognition of resistance practices, from the detection of a substantial building heritage abandoned throughout the city, but above all from the need to re-discuss the categories in which citizens and non-citizens are organized with their housing, work, cultural and recreational needs. CIRCO is an acronym that in Italian is configured as indispensable house for civic recreation and hospitality. CIRCO proposes a rethinking of the system of reception and intends to recognize and learn from the practices of construction of the living environment of migrants, asylum seekers and refugees in formal and informal contexts. In this sense, CIRCO has the objective of promoting the construction of autonomy paths for the right to live. The project offers new welfare services based on the period of permanence and the economic possibilities of each person, with the aim of generating new ways of reciprocity and coexistence between permanent and temporary inhabitants of the city. Although difficult to summarize, the main methodological assumptions underlying the CIRCO project are shown below.

\section{From Reception to Hospitality}

CIRCO was born from other previous projects, two walks organized by the Stalker Lab: the first, on the theme of contemporary ruins, was called Walk out of Contemporary 2016 [Romito, 2015]; and the second, which retraced the path of Aeneas on Italian soil, called Xeneide 2017 [Stalker, 2017]. From these projects, CIRCO inherits an approach that looks back towards the art of hospitality of an ancient world. This concept takes up the Greek word xenía, the gift that the host gives to the guest, but more generally concerns the complex of reciprocal rules that underlie hospitality, which was sacred to all the ancient world and which today has always more lost in meaning and has been replaced by the word welcome. As Virgil handed down to us in the epic poem Aeneid, Aeneas, ancestor of the founders of Rome Romulus and Remus, arrives from Troy after a difficult journey across the Mediterranean. He arrived in Italy as a refugee, bringing his foreign blood to mix and join to those of the latins. He reaches the Palatine hill (already characterized by the presence of ruins, even before the existence of the city) and he meets Evandro the Greek, to whom was already connected from a previous bond, the xènia, the gift of hospitality. That gave origin to the latin hospitalitas. From Evandro and Aeneas until Romulus and finally to the city of Rome, cyclically distinguished by its ruins reactivated by foreigners who inhabit it. With the aim of taking care of this cultural heritage, the main idea of CIRCO is to counterpose to the unilateral approach of the concept of reception the more reciprocal concept of hospitality. Hospitality derives from the Latin hospitalitas that gave origin to the enantiosemic word hospes, which means both the one who host and the one who is hosted, duality that persist in the Italian language. The reciprocity of the act of hosting somebody, that whoever he or she is, or comes from, is welcome because he/she could bring a wonderful, especially immaterial, gift, made of stories, legends and culture of faraway lands. This approach wants to underline that the true gift is the meeting of foreign people. Hospitality wants to promote the exchange of cultures towards a process of coexistence which would hopefully led to building new places of common practices. Once again, contrasting the attitude of the reception structures, where people are treated as if they were only asking (food, blankets, warmth, etc.) and with the presumption that they have nothing to bring us as gifts.

\section{A Waste Constellation}

"But when we look at waste and scars with interest, we may learn how to integrate them into a continuous cycle of use. [...] but if we mean to integrate waste into the cycle of use, we must modify our automatic squeamishness. [...]. Since we expect to continue to produce waste, we must be prepared to reuse, even enjoy, that waste continuously" [Lynch, 1972]. With these words, Lynch invited architects and urban planners of the early seventies to a substantial revolution of thought. At a time when the society of consumption and overproduction was beginning to show the first unmistakable signs of failure, Lynch, and others with him, invited us to look through these signs, to find potential and beauty in what until then had been catalogued as waste, as scrap (scarto in italian). CIRCO 
did exactly that.In this perspective, in fact, CIRCO Lab, together with the students of the semester 2017-18, carried out an abandoned and/or underused buildings' mapping in the municipal territory. The main goal was to highlight the amount of places where CIRCO, a policy of rethinking the way to host, live and experience the public city, could find a home. At the core of this work is the awareness that mapping the disused building stock, especially public property, is one of the fundamental and most urgent operations in order to direct urban governance towards zero land consumption policies, integrated urban regeneration and solutions to the housing problem.

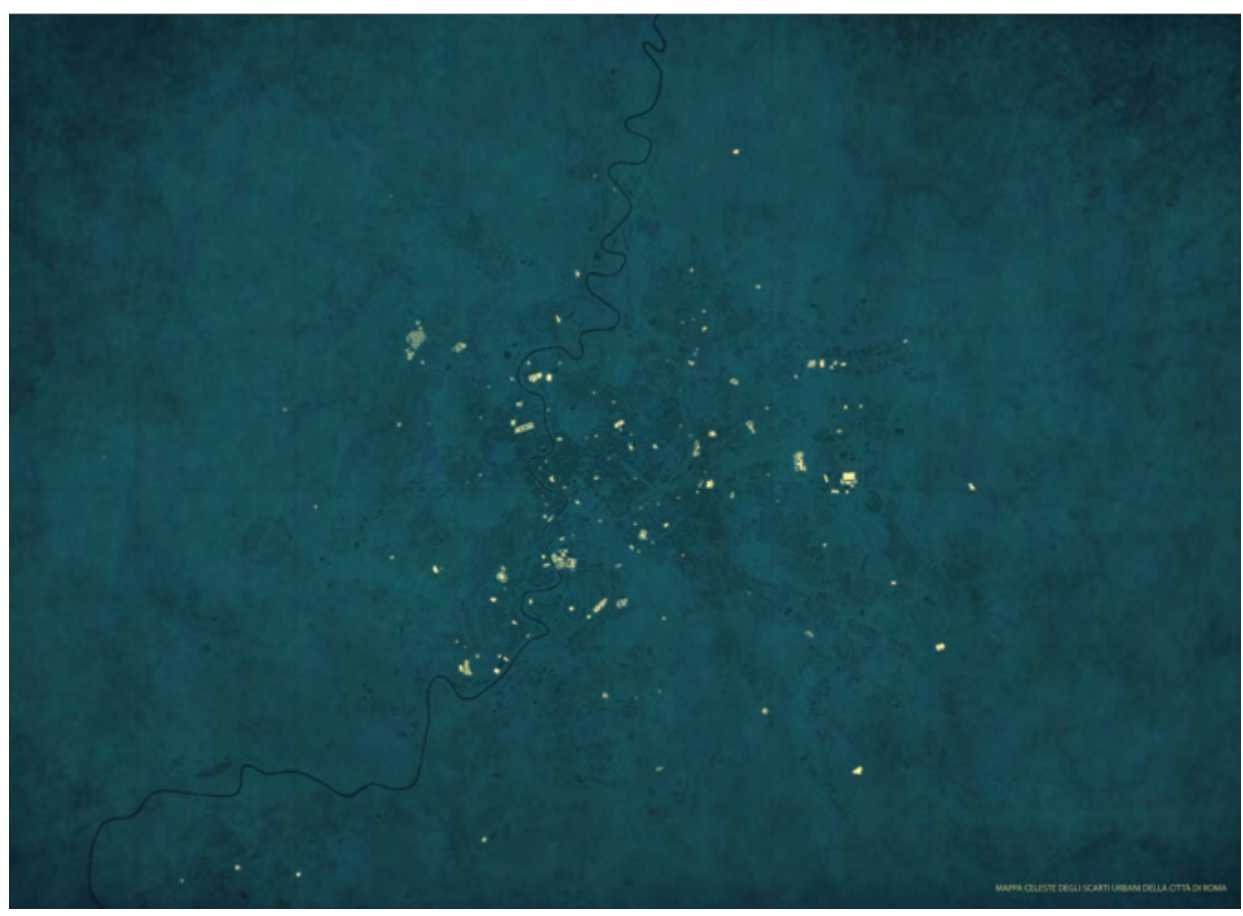

_ Figure 1: Waste constellation map.

The work carried out by CIRCO Lab involved several groups of students working on the reconnaissance of different types of abandoned space, as many as the most outstanding "abandonment" categories that recent socio-economic transformations have produced within the urban territory: health structures no longer used, sports centres no longer attractive, military structures, large spaces for storage and sorting of urban mobility now abandoned, the huge amount of places dedicated to education and culture (such as schools, cinemas, theatres) as well as the increasingly dense underused ecclesiastical heritage and, finally, the many buildings linked to production, such as factories or warehouses, containers of activities that the city has expelled to its margins but has not yet replaced. A first substantial mapping has emerged, certainly partial and implementable, but which provides a very clear picture of the amount of this heritage. From this mapping emerges what we wanted to call a waste constellation: remnants of urban transformation processes. This heritage was abandoned for a variety of reasons, often in view of subsequent speculation, nonetheless, it, constitute a resource of extremely significant consistency. Finally, it is necessary to consider that over 754,000 buildings in Italy are unused because they are abandoned, unsafe or unfinished, approximately $5.2 \%$ of the total assets.

\section{The Economic Strategy: Mixitè, Progressivity and Informal Approach}

CIRCO's economic strategy refers to new methods of social regeneration, capable of compensating 
or the contribution of PAs, involving third sector entities, traditionally destined for the production of goods and services, aimed at the redistribution of resources in favor of disadvantaged subjects, based on the different forms of donations or voluntary work. Social enterprises guarantee productive initiatives, at the base of which there is a goal other than the profit of the owners or the maximization of their economic advantages [Yunus, 2008]. A new generation of urban actors, capable of framing their corporate vision by combining the use of public fixed territorial capital, the creation of social value, the ability to intercept public funding, the use of innovative financing instruments (such as ethical finance) in a new welfare model. It is also in the economic-functional mix that CIRCO substantiates its strategy with the idea of a context in which the inhabitants self-manage the provision of services jointly with the social managers (legal counters, clinics, reading rooms, cultural exhibition spaces, etc.). These activities, guarantors of a social value, are economically unsustainable as they cannot be priced and can be defined economically "cold". On the other hand, activities that include fees or tariffs at market prices, defined as "hot", can be included, which allow to cover costs, remunerate the work done and generate profits. From the circular point of view of CIRCO projects, if the managers are jointly responsible for the social purposes, the partial reintegration of profits in support of the cold functions is conceivable. Then, there are "lukewarm" functions that provide services with different rents than the market, alternating groups of users in relation to the type of service. A functional composition capable of compensating the diseconomies related to the more social aspects of space, thanks to the surplus produced by the most profitable functions, can represent a virtuous mechanism for CIRCO projects.

Further improvement of the economic profile can be obtained with the concepts of temporariness and progressivity. The first aspect refers to flexible spaces, convertible to different uses for different users, compartmentalized, capable of transforming themselves, expanding the spectrum of services, activities and times of use of the CIRCO, with a consequent increase in user flows. Progressivity, on the other hand, aims to manage the project in phases: the immediate activation of all activities can represent an unsustainable economic effort, while the progressive activation of the functions can allow a feasibility, linked to the positive cash flows of each phase. Finally, for years, reuse for social purposes has been activated through informal practices, often connected with the unauthorized use of the space in which numerous services are managed, capable of diversifying from the market, in two specific directions: 1) lower prices or tariffs; 2) socializing methods of use. The first aspect concerns the possibility of including people in unfavorable economic conditions, thanks to the containment of the costs that informality allows (availability of space, less bureaucracy, voluntary contributions, micro-credit networks, exchange of services based on asymmetric utilities and not on exchange of equivalents, self-construction, self-production, etc.). The second aspect consists in the diversification of the fruitful modalities of the service; in traditional consumer experiences, sociality is limited to the consumption of the good or service. In informal practices, the social relationship goes beyond the fruition by showing itself in interferences with the management of the service. In the services offered by informal spaces, in addition to access to a reduced economic level, if you share the basic social premises of the space that provides the service, you can actively take part in the decision-making and management activities of the space and the service itself. This dual fruiting method (almost never offered by the market) allows to maximize, in addition to the utilitarian aspects related to consumption, also relational and social satisfaction, intercepting the desire for active and conscious citizenship. This practice, applied to many services offered by some informal experiences, such as popular sports clubs, time banks, tea rooms, wine bars, social kitchens / restaurants, popular canteens, music rehearsal rooms, exhibition spaces, consultors, legal counters, housing solutions, emergency and many other activities, could be a good insert in CIRCO's strategy.

\section{A Different Way of Living}

The space that CIRCO offers is a sort of caravanserai, a nomadic and sedentary place at the same time, where you can experience ways of life in common between permanent residents and transient inhabitants. The strategy is to hybridize housing with all categories that seek space in the city such as off-site students, travellers, new arrivals (expats, migrants, asylum seekers, etc.). The strategy is 
rooted in the exploration and expansion of the category of temporary inhabitants, questioning what the various subjects that can refer to it share and what distinguishes them: from access to basic public services to legitimacy on national soil, from the objectives to be to complete in a given period the desire for local roots. Having learned the urban lesson of mono-functionalism, it is obvious that it is a good practice to hybridize living with mixed functions and services, breaking the consumer/producer dichotomy, dressing the inhabitants towards a model that, in another context, Jeremy Rifkin has defined prosumer (producer and consumer together). In CIRCO, the residence is connected to services (some of a pertinent nature and others open to the rest of the city) allowing the use of innovative solutions of the inhabited space based on collaboration and sharing.

\section{The didactic approach}

In the last three years, starting from the didactic experiences, the laboratory has worked with the students on the above-mentioned themes and on other parallel and complementary. The didactic approach is based on an open, indeterminate and process-oriented planning, has led students to learn what the city had to teach, for better or for worse. Car parks turned into tent cities were visited, where thanks to volunteering anyone is welcomed, as a person, without asking for documents. They institutional structures of the so-called reception, the structures of the Catholic world and many of the places of informal living in the city of Rome were visited. We asked the many people who accompanied us and made their knowledge available, intervening in the courses, hosting us in their places of action. On the next page are shown some design examples of the imagery to which the project relates, developed over the three years of the Architectural and Urban Design Laboratory at the second year in the Master Degree in Urban Studies, and some Degree Theses discussed at the Department of Architecture of Roma Tre University.

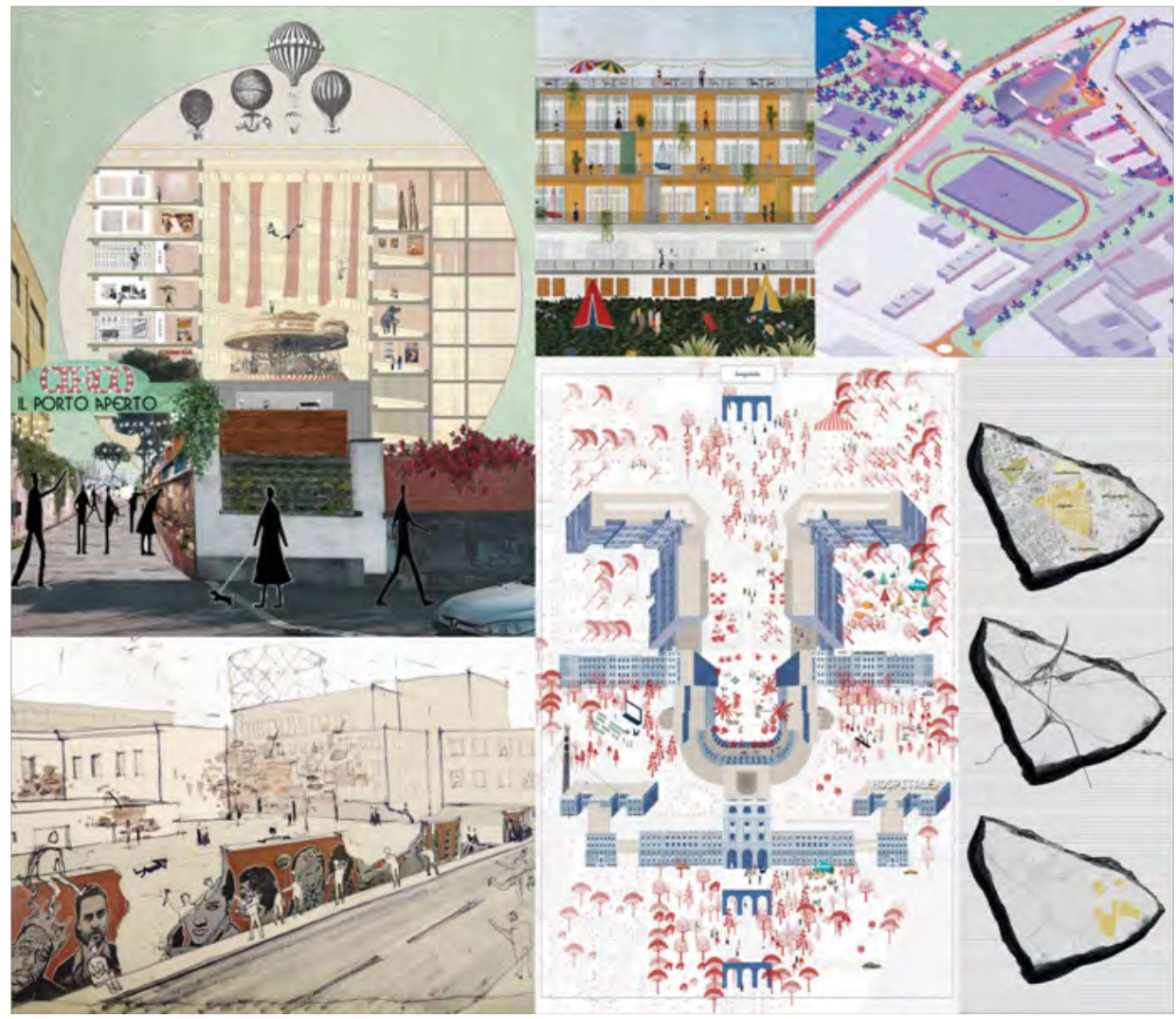




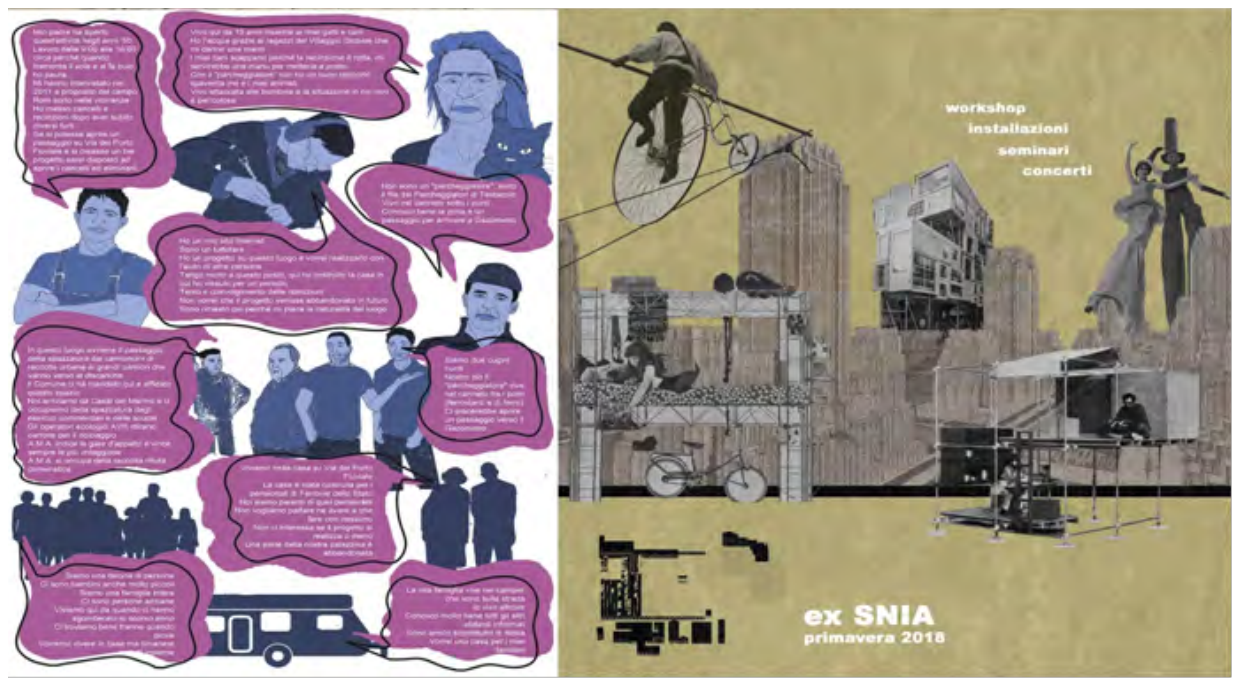

_ Figure 2. CIRCO. The strategy of CIRCO needs to be adapted with both socio-territorial resources of the context and the variety of architectural typologies where is inserted. The figure shows some of the most significant project made by CIRCO's students from 2017 to 2020. The scale of the project, the network of actors involved, the amount of physical transformations as well as the life cycle of the project vary according to what kind of "urban waste" CIRCO meets, from the reactivation of a small abandoned school to the redesign of the open spaces of an entire neighbourhood. The projects are available at https:// laboratoriocirco.wordpress.com/.

\section{CONCLUSIONS}

The Lab CIRCO is a research in progress, and as such, even before providing answers, it allows to ask yourself a series of questions. Among the various questions, one concerns its role as a policy for the temporary use of disused buildings, a character that can be easily intercepted by strategies for the enhancement of the built heritage by private owners - or even contribute to gentrification processes and other excluding urban transformations. CIRCO offers an inclusive place, where the problems of the city become resources thanks to the synergies that can be explained by having dealt with them together and not separately. A house in which space is made for those seeking and hospitality and those who wish to host. A world of worlds [Piasere, 1999] in which everyone offers his skills to be put into play for everyone. An experimental and normogenerator living, which imagines, builds and proposes new rules and regulations. A civic architecture that challenges the city by showing itself indomitable, irreducible and therefore indispensable. To verify its effectiveness CIRCO needs an experimental application on a real case and the Laboratory is working in this direction. Methodologically, in design terms, the Lab CIRCO has applied to the case of a Roman Public Institutes of Assistance and Charity (IPAB, Istituto Romano San Michele) the rethinking of abandoned and underused spaces in a circus key. After about six months of permanence of the teaching activities in the building complex, the planning put in place has clashed with the different political wills of the complex that have, to date, frustrated the intent. Despite the various difficulties, CIRCO has identified a lot of spaces within the city and is ready to assemble its tent and kick off the show. 


\section{REFERENCES}

_ Campesi G. 2018. Between Containment, Confinement and Dispersal: The Evolution of the Italian Reception System Before and After the 'Refugee Crisis, in "Journal of Modern Italian Studies" 2018.

_ Eurostat. 2019. Crime statistics. Available at: https://ec.europa.eu/eurostat/statistics-explained/index.php?title=Crime_statistics. Accessed 01.02.2020.

_ IOM. 2018. World Migration Report. Available at: https://www.iom.int/sites/default/files/country/ docs/china/r5_world_migration_report_2018_en.pdf. Accessed 01.02.2020.

_ Leonardo L. 1999. Un mondo di mondi. Antropologia delle culture rom. L'Ancora, Napoli.

_ Lynch K. 1972. What Time is this Place? MIT Press, Cambridge, USA.

_ Romito L. 2015. "Walking out of Contemporary", in Mitrasinovic M. (Ed.) Concurrent Urbanities: Designing infrastructures of Inclusion. Routledge, 2015.

_ Stalker. 2017. Xeneide il dono dell'altro. http://articiviche.blogspot.com/2017/03/avviso-per-gli-studenti-di-arti-civiche.html. Accessed 01.02.2020.

- Walters W. 2009. Foucault and the frontiers: notes on the birth of the humanitarian border. Brokling, U., Krassman, S., Lemke, Th. (Ed.), Governmentality: current issues and future challenges. Routledge, London.

- Yunus M. 2008. Un mondo senza povertà. Feltrinelli. Milano. 